\title{
How much can be saved by changing the regulation of the apartment house boiler room
}

\author{
Petr Novotný, Jan Hujer \\ TU of Liberec, faculty of Mechanical Engineering, Department Power Engineering Equipment, Czech Republic
}

\begin{abstract}
Boiler room for apartment building is in operation since 2009 and data are collected for cost evaluation. Question arises after a minor reconstruction. How much energy has been saved? The article selects and processes data that was available. It shows that the importance of the heating circuit pump control cannot be underestimated or overestimated. The article derives savings from gathered data.
\end{abstract}

\section{Introduction}

An older apartment building disconnected from the central heat supply in 2009 and built its own gas boiler room. It operated according to the original project until 2016. During this year, a change of regulation of the house heating was made by means of a mixing valve in the heating circuit.

There are two logs on boiler room operation, one of which contains information on energy consumption. This information is written manually twice during the month. By evaluating these data, we obtain information about the energy consumption before and after reconstruction.

\section{Project of 2009}

Three condensing boilers operate in cascade and prefer hot water. Boilers are controlled by equithermal regulation, which uses historical data of approximately three days to calculate the heating water temperature.The boilers are connected via a torus to the heating system with a separate heating pump. The individual risers of the house are controlled by differential pressure regulators, the radiators have thermostatic valves. The DHW heating in two water tanks is controlled by the control unit and a separate charging pump, the heating circuit pump is switched off in the case of DHW heating. The water for the heating of the containers is taken behind the toroid Fig. 1. According to the project, when the hot water supply is depleted, the heating system pump is switched off and the hot water heating pump switched on. Water heating is performed by all three boiler units. Their power is greater than that of the hot water heat exchanger. Heating time varies depending on the current consumption. Water tanks have a capacity of 500 liters, average daily consumption of hot water is about $4 \mathrm{~m}^{3}$. Heating does not start after the hot water supply has been depleted but sooner. It is due to the position of the thermometer in the tank and the setting of the minimum temperature. In reality, due to losses in hot water circulation, the amount of heated water is doubled (corresponding to gas consumption for water heating).

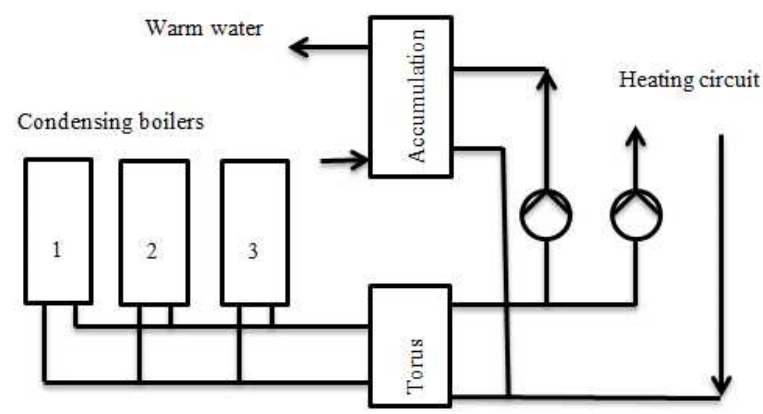

Fig.1. Simplified scheme of engagemet from the year 2009

Hot water supply system has a separate circulating pump that interrupts circulating during the night hours. During the day circulation occurs every 15 minutes for a duration of about 5 minutes. The duration of hot water heating throughout the day can be estimated in a length of 15 extremely up to 25 minutes. Heating system starts gradually after completion of hot water heating. First, the heating circuit pump is started and when boiler water is cooled below required heating water temperature, boiler units are gradually started up. This extends the time of reduced heat supply to the radiators and, in addition, opens the thermostatic heads and increases the flow of heating water. If we consider a minimum of 12 heating cycles per day (in fact, it is more) for 15 minutes, it is a three-hour interruption of the heating water supply over a day, which is logically replaced by high temperature in the heating system and a larger amount of heating water. Additionally, the pump (in Adaptive Auto mode) looks for the optimum setting, but restarts every time it is turned off [1].

The control unit has enabled mixing valve control and simultaneous DHW and heating. In 2009, however, the designer described this possibility of installing a mixing

*Corresponding author: petr.novotny@tul.cz 
valve as something a expensive and unnecessary when the pump runs in autoadaptive mode. Grundfos Magna $50-120$ pump operated in this setup often at $60 \%$ of the delivered quantity, exceptionally at $40 \%$. At the start of the heating circuit, it increased the output to $100 \%$ in the short term. The pump has a min. $35 \mathrm{~W}$ and max. $800 \mathrm{~W}$. It does not measure the amount of supplied water but calculates from the pump operating parameters.

\section{Reconstruction}

After the heating season in 2016, the boiler room was reconstructed. Mixing valve has been mounted in the heating circuit in Fig. 2. The mixing valve is at the inlet of the heating circuit pump. The pump has been set to Constant Output Pressure at a discharge height of 3 meters. The pump has not been set to auto-adaptive mode. The setpoint temperature of the heating water has been lowered by two degrees, because the heating takes place without interruption throughout the day.

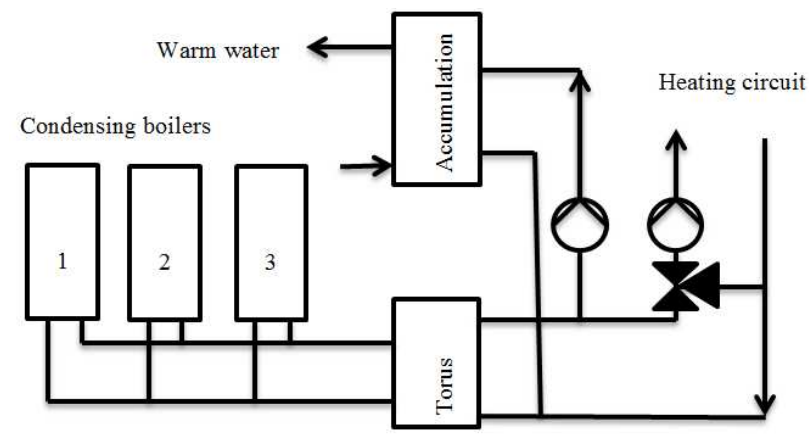

Fig. 2. Simplified diagram of 2016

After reconstruction, when water temperature in the storage tank drops below the set value, the DHW charging pump is triggered. At the same time, if all the boiler units are not working, they start and gradually increase the power. Boiler output temperature is $80^{\circ} \mathrm{C}$. The three-way valve adjusts the outlet temperature to the heating circuit according to the outside temperature. It responds with a delay, so that the heating water temperature increases by several degrees during DHW heating. The control unit gradually eliminates this temperature increase, but only after the hot water heating has finished. In the heating season 2016/17, during the boiler inspections, the pump operated according to display when it froze at $40 \%$ of the supplied amount of heating water. Most of the time pump displayed $20 \%$.

\section{Measured operation data}

Data recorded in the log is written manually. Data records are in some cases longer than 15 or 30 days. This makes evaluation difficult, but on the other hand it was important to provide this information for economical comparison of energy consumption and the amount of finance for the boilers room operation.

Data from 2010 to 2014 were selected from the log for months from October to April Fig. 3. Data on average monthly temperatures were obtained from the Czech portal TZB for calculating degree days (on link « vytápění, tabulky a výpočty, výpočet denostupňů ») [2]. Here are the meteorological data from Liberec airport. The airport is situated on the outskirts of the city at an altitude of $400 \mathrm{~m}$ above sea level.

It should also be noted that there are differences between the temperatures of different districts of the city and the airport. The city is located in hilly terrain with various buildings and vegetation. Differences in temperatures are not constant but are not critical to our measurement and analysis. These temperature differences are not critical for boiler room data and are attenuated by the house and system dynamics. Monthly data on energy consumption are mainly exposed to errors in the uneven recording of operational data in the boiler room.

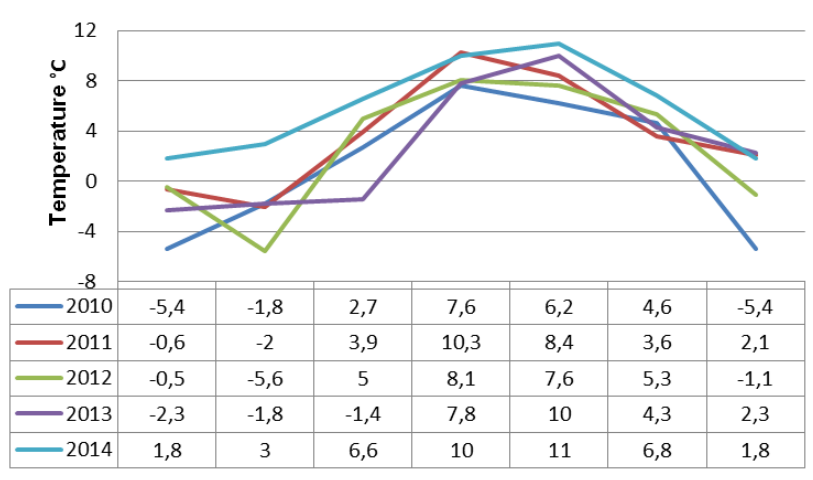

Fig. 3. Monthly temperature data

\subsection{Electricity consumption}

\subsubsection{All monthly data before reconstruction}

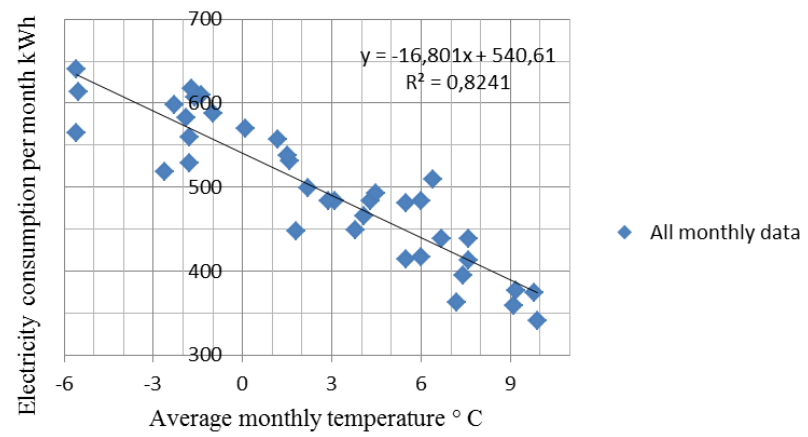

Fig.4. All monthly data

The uneven write period ranges from 28 days to 33 days in Figure 4. This is naturally reflected in the reliability of the approximation result using the formula equation.

\subsubsection{Selected data for 30 and 31 days}

All data that did not meet the condition was removed from the file. The confidence factor has improved, but the impact of one day's tolerance is high. For example, where the average monthly temperature is $-5.4^{\circ} \mathrm{C}$ for two months of 30 and 31 days of Figure 5. Other inaccuracies 
are, for example, that the month, which has 31 days, has recorded data for only 30 days and vice versa. We can improve this by using a longer time span. During the year we have 7 months. We divide them into 3 autumn and 4 spring.

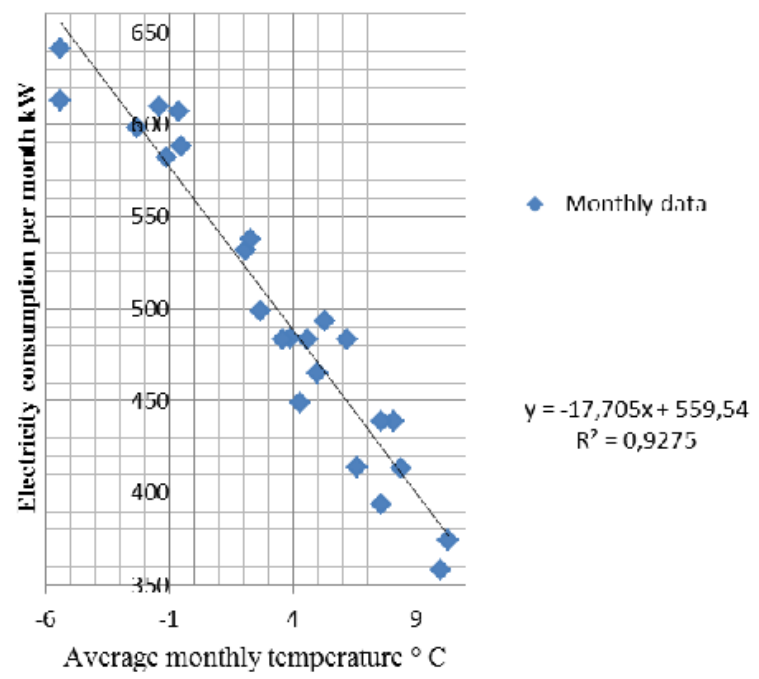

Fig.5. Monthly electricity consumption in kWh besed on average monthly temperature

\subsubsection{Editing data}

Table 1. Autumn

\begin{tabular}{|l|r|r|r|r|r|}
\hline Year/autumn & 2010 & 2011 & 2012 & 2013 & 2014 \\
\hline Temperature ${ }^{\circ} \mathrm{C}$ & 1,566 & 4,033 & 3,1 & 5,533 & 6,533 \\
\hline Electricity kWh & 1607 & 1428 & 1516 & 1363 & 1313 \\
\hline
\end{tabular}

Table 2. Spring

\begin{tabular}{|l|r|r|r|r|r|}
\hline Year/spring & 2010 & 2011 & 2012 & 2013 & 2014 \\
\hline Temperature ${ }^{\circ} \mathrm{C}$ & 0,775 & 2,9 & 1,75 & 0,575 & 5 \\
\hline Electricity $\mathrm{kWh}$ & 2066 & 1983 & 2057 & 2106 & 1756 \\
\hline
\end{tabular}

The sum of the months will be ninety and one hundred and twenty days where the error one day has little effect. Table 1 shows the results for October, November and December (Autumn) and Table 2 for January, February, March and April (Spring).

According to the results in Fig. 6, the dependence of the energy consumption on the average temperature can be considered as linear in the range of the measured data.

\subsection{Gas consumption}

Similar inaccurate data is also on gas consumption. Another error that affects measured data is warm water. The annual consumption is in Table. 3. The average consumption of an apartment building per year is

Table 3. Warm water

\begin{tabular}{|l|l|l|l|l|l|l|l|}
\hline Year & 2010 & 2011 & 2012 & 2013 & 2014 & 2015 & 2016 \\
\hline $\mathrm{m}^{3}$ & 1595 & 1522 & 1518 & 1539 & 1594 & 1543 & 1533 \\
\hline
\end{tabular}

$1549 \mathrm{~m}^{3}$ and a deviation range from $+3 \%$ to $-2 \%$ in different years.

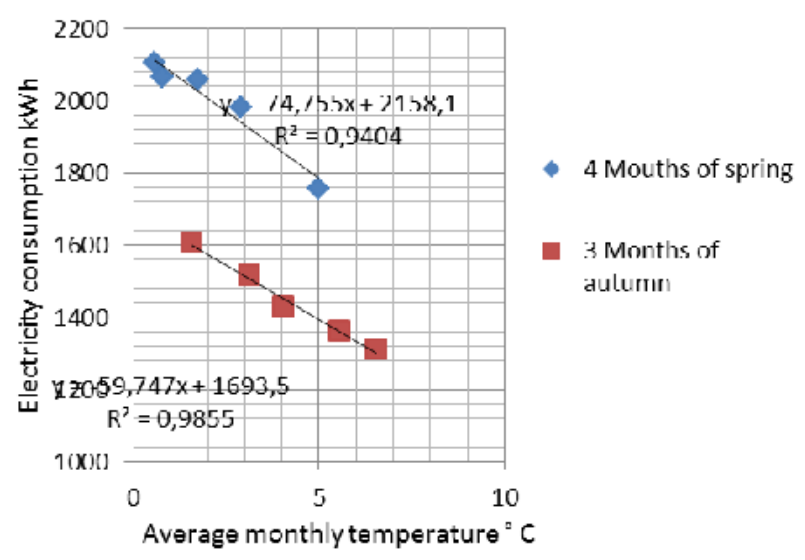

Fig.6. Dependence of consumption on temperature

Monthly differences are similar (\%) in water consumption. In winter, the water is colder.

The temperature of the water at the inlet before heating is not measured and the consumption of gas for heating the water is not measured. The consumption of gas for DHW heating can be determined outside the heating season. Water heating will be viewed as a disorder that affects some result.

\subsubsection{Selected data for 30 and 31 days}

In Fig. 7 the data is evenly loaded with error. There is a relatively high confidence coefficient of 0.98 at line approximation. Improving the reliability factor by further editing due to data acquisition inaccuracies can not be expected.

\subsubsection{Editing data}

We will perform the sum of months October, November and December (autumn) and the remaining 4 months as "Spring". It is clear from Figure 8 that further improvement of results has not occurred even though we have been working with more days (90 and 120). We will use the monthly gas consumption data to evaluate the reconstruction.

\section{Reducing energy consumption}

The reconstructed boiler room was in operation from autumn 2016 until spring 2017. However, we can't use data for all months, because some records are missing or are deducted at the wrong time interval.

It has been confirmed that the electricity consumption for this house is changing linearly proportional to the average temperature. This is a dependence on the measured temperature in the evaluated period. Whether this dependency applies to temperatures up to $-15{ }^{\circ} \mathrm{C}$ is not confirmed. Before the reconstruction and after the reconstruction, the boiler room worked without damping. The house has small apartments and is inhabited by a wide range of people from old citizens to families with small children (not the exception of a four-person family in a $1+1$ apartment). Every apartment occupant adjusted the temperature according to his own needs by adjusting the thermostatic valve. Uninterrupted heating increased 
satisfaction of the residents and removed noise caused by dilatations, which could not be eliminated for years.

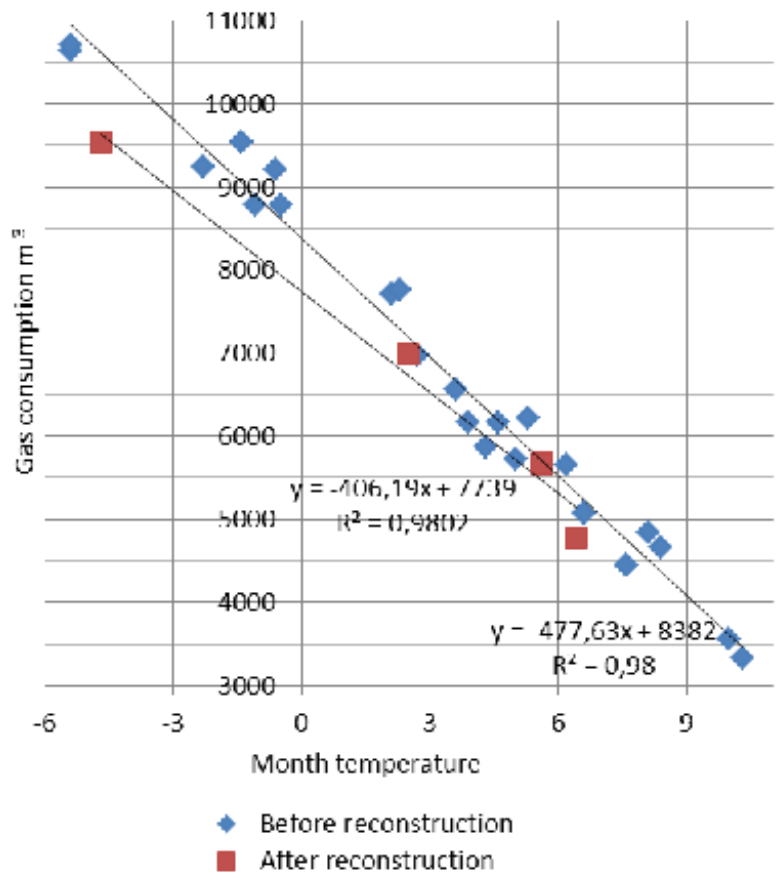

Fig.7. Gas consumption data for 30 and 31 days

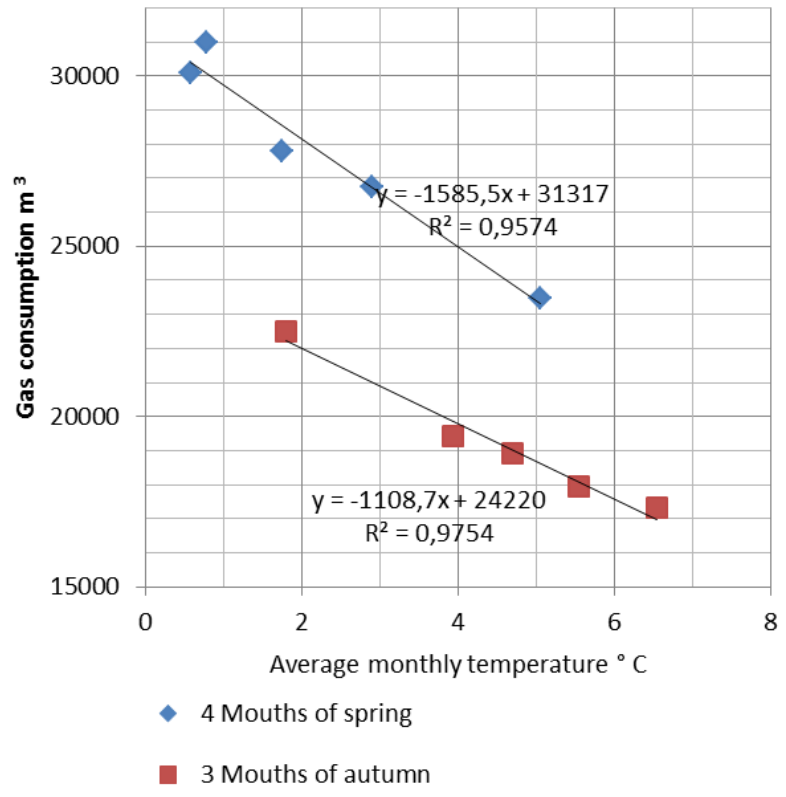

Fig.8. Dependence of consumption on temperature

In the heating season 2016/17, the adjustments made were reflected in electricity consumption. Although both pumps were operated at the same time and the mixing valve actuator was operating, there are savings in electricity consumption. Linear equations obtained by simple regression can be considered to be sufficiently accurate to estimate the savings in electricity consumption. In autumn 2016 after reconstruction, when the average temperature in three months (autumn) was $2.9^{\circ} \mathrm{C}$, consumption was $1342 \mathrm{kWh}$ boiler room. If the reconstruction was not carried out, the linear model consumption would be approximately $1514 \mathrm{kWh}$. The saving is about $11 \%$ of the electricity. In the spring of 2017 , at an average temperature of $1.5^{\circ} \mathrm{C}$, and a consumption of $1739 \mathrm{kWh}$, savings of approximately $274,7 \mathrm{kWh}$ were calculated, is $13 \%$ of electricity.

Total annual electricity consumption averages around 4 MWh. Total consumption decreased by about $446 \mathrm{kWh}$, which is $10 \%$.

Figure 7 shows five months of gas consumption in the boiler room after reconstruction. Statistically, this is an insignificant amount dat that can't be used even if the reliability is high. Using the results shown in Figure 8 is worse coefficient reliability. Usable data is for a period of four months (spring) in 2017, when the average temperature was $2.15^{\circ} \mathrm{C}$. The gas consumption was $26880.1 \mathrm{~m}^{3}$ which according to the linear model corresponds to $27908 \mathrm{~m}^{3}$ of gas for this average temperature. The difference is therefore $1027.9 \mathrm{~m}^{3}$ and corresponds to the inaccuracy of the linear model. The gas saving can't be determined from the measured data because it is a small quantity ranging from 2 to $4 \%$. Savings can be achieved by modifying the boiler room. These savings are not significant but ultimately reduce the energy requirements to ensure thermal comfort in a residential building.

\section{Conclusion}

- The data obtained was not accurate to detect gas savings

- Significant savings are in electricity consumption

- We can only estimate gas savings of around 2\%, which at an annual consumption of 50 thousand $\mathrm{m}^{3}$ is $1000 \mathrm{~m}^{3}$ of gas

\section{Acknowledgment}

This publication was written at the Technical University of Liberec as part of the project "Experimental and numerical investigation in applied fluid mechanics and energy devices, no. 21124" with the support of the Specific University Research Grant, as provided by the Ministry of Education, Youth and Sports of the Czech Republic in the year 2017.

\section{References}

1. Adaptive Selection of Control-Curves for Domestic Circulators; Carsten Skovmose Kallesøe*, Niels Bidstrup*, Manfred Bayer; *Grundfos Management A/S, Poul Due Jensens Vej 7, DK-8850 Bjerringbro, Denmark (e-mail: \{ckallesoe,nbidstrup\}@grundfos.com)

2. Data Available May 31, 2017 at http://vytapeni.tzbinfo.cz/tabulky-a-vypocty/103-vypocet-denostupnu

3. P. Novotný, workbook boiler rooms, unavailable. 